\title{
Article
}

\section{The Effect of Sleep Quality on Pain in Chilean Individuals with Musculoskeletal Disorders}

\author{
Claudio Bascour-Sandoval ${ }^{1,2} \mathbb{D}$, Hellen Belmar-Arriagada ${ }^{3,4}{ }^{\mathbb{D}}$, Javier Albayay ${ }^{5}$, Claudia Lacoste-Abarzua ${ }^{1}$, \\ Diego Bielefeldt-Astudillo ${ }^{1}$ (D), Rubén Gajardo-Burgos ${ }^{6} \mathbb{D}^{\mathbb{D}}$, Mirko Vidal-Torres ${ }^{6,7}$ \\ and Germán Gálvez-García ${ }^{8,9, * \mathbb{D}}$
}

check for updates

Citation: Bascour-Sandoval, C.; Belmar-Arriagada, H.; Albayay, J.; Lacoste-Abarzua, C.; Bielefeldt-Astudillo, D.; Gajardo-Burgos, R.; Vidal-Torres, M.; Gálvez-García, G. The Effect of Sleep Quality on Pain in Chilean Individuals with Musculoskeletal Disorders. Int. J. Environ. Res. Public Health 2021, 18, 11370. https:// doi.org/10.3390/ijerph182111370

Academic Editors: Gerard A. Kennedy and Russell Conduit

Received: 27 September 2021

Accepted: 27 October 2021

Published: 29 October 2021

Publisher's Note: MDPI stays neutral with regard to jurisdictional claims in published maps and institutional affiliations.

Copyright: (c) 2021 by the authors. Licensee MDPI, Basel, Switzerland. This article is an open access article distributed under the terms and conditions of the Creative Commons Attribution (CC BY) license (https:/ / creativecommons.org/licenses/by/ $4.0 /)$.
1 Grupo de Investigación Clínica en Kinesiología, Carrera de Kinesiología, Universidad Autónoma de Chile, Temuco 4780000, Chile; claudio.bascour@ufrontera.cl (C.B.-S.); claudia.lacoste@uautonoma.cl (C.L.-A.); diego.bielefeldt@uautonoma.cl (D.B.-A.)

2 Departamento de Medicina Interna, Universidad de La Frontera, Temuco 4780000, Chile

3 Programa de Magíster en Terapia Física con menciones, Universidad de La Frontera, Temuco 4780000, Chile; hellen.belmar.a@gmail.com

4 Facultad de Salud y Ciencias Sociales, Universidad de las Américas, Concepción 4030000, Chile

5 Center for Mind/Brain Sciences, University of Trento, 38068 Rovereto, Italy; javier.albayay@unitn.it

6 Instituto de Aparato Locomotor y Rehabilitación, Universidad Austral de Chile, Valdivia 5090000, Chile; ruben.gajardo@docentes.uach.cl (R.G.-B.); mirko.vidal@uach.cl (M.V.-T.)

7 Centro Universitario de Rehabilitación, Universidad Austral de Chile, Valdivia 5090000, Chile

8 Departamento de Psicología, Universidad de La Frontera, Temuco 4780000, Chile

9 Département de Psychologie Cognitive \& Neuropsychologie, Institut de Psychologie, Laboratoire d'Étude des Mécanismes Cognitifs, Université Lyon b, 69676 Lyon, France

* Correspondence: german.galvez@ufrontera.cl

Abstract: Poor sleep quality (SQ) negatively affects pain associated with musculoskeletal disorders (MSD). As the level of economic development of a country determines its sanitary conditions, these can influence the sleep-pain relationship; therefore, it is relevant to generate evidence in the population with MSD in developing countries. This cross-sectional study sought to determine the effect of poor SQ on pain in Chilean individuals with MSD, controlling for sex and duration of pain (in months). Method: A total of 228 individuals were included. SQ was measured with the Pittsburg Sleep Quality Index (PSQI), pain (intensity, interference and distress relative to pain) was measured with visual analog scales. Structural equation modeling (SEM) was performed to analyze the effect of SQ on pain. Results: A high frequency of poor SQ was present in the studied group, and was more prevalent in women. The SEM model evidenced that poor SQ predicts greater pain. Sex influences sleep quality and pain, but not pain duration. Conclusions: These findings indicate that poor SQ predicts higher pain in MSD and that women exhibit worse SQ and more significant pain than men. Our findings support that SQ should be considered in the comprehensive approach to pain in individuals with MSD.

Keywords: sleep quality; musculoskeletal disorders; musculoskeletal pain; chronic pain; pain

\section{Introduction}

Musculoskeletal disorders (MSD) are a major public health issue [1] characterized by the presence of pain and frequently associated with sleep disturbances resulting in poor sleep quality (SQ) [2]. Thus, there is increasing research interest in the link between SQ and pain in individuals affected by MSD.

Although some studies have described the relationship between SQ and pain as bidirectional [3], recent evidence indicates that SQ predicts pain more strongly than pain predicts SQ [4-6]. Poor SQ can alter key processes in pain perception. For instance, total and partial sleep deprivation has been shown to interfere with pain processing, inducing hyperalgesia in pain-free subjects and individuals with MSD [5,7]. Furthermore, poor 
SQ can contribute to acute pain continuing, acting as a risk factor for developing chronic pain $[8,9]$.

Other relevant factors, such as sex and pain duration, influence SQ and pain perception in individuals affected by MSD. Women report a higher frequency of poor SQ and pain than men [10,11], and a longer duration of pain has been associated with poor SQ [10] and higher perception of pain [12]. However, other studies have not established this connection and it remains controversial [13,14].

Most of the literature on the relationship between SQ and pain in individuals with MSD has been generated in high-income, English-speaking countries, such as the United States, Canada, the United Kingdom, Finland, Israel, and Norway, with a few studies in non-native English-speaking countries like Brazil $[4,15,16]$. Mainly, investigations in Hispano-American countries concerning the relationship between SQ and pain in individuals with MSD are limited and inconclusive [17-19]. For instance, two studies found that poor SQ is associated with more musculoskeletal pain in individuals with chronic MSD [17] and sleep disorders [18]. However, the study by Covarrubias et al. [17] lacks clarity about the treatment of missing data and reporting of their results is deficient. Mariños et al. [18], for their part, present a poor characterization of the sample and non-validated instruments for their variables. The study by Navarro-Aquino et al. [19] found no significant association between SQ and pain but, similar to the others mentioned, presents an incomplete statistical analysis and poor methodological and results reporting. In addition, the three only measured one dimension of pain (i.e., intensity), which together with methodological flaws, can significantly limit their scope.

Due to the preceding works, the investigation by Stubbs et al. [20] becomes relevant. These authors carried out a study based on the general population in different countries (without a specific diagnosis), reporting variation in the SQ-pain association between middle-income and low-income countries. They highlight the need to continue generating studies in various socioeconomic and cultural realities given that differences between countries (i.e., access to analgesics or sleep medications, or non-pharmacological interventions such as physiotherapy/psychological treatment) and cultures (i.e., traditions or religious beliefs) may modify this relationship [20]. This is highly relevant when assessing the SQ-pain association in individuals with MSD.

Due to the negative impact that MSD represent, it is essential to identify factors that affect pain and represent a barrier in their treatment, especially those that are modifiable, such as a poor SQ [21,22]. This would guide therapeutic strategies, especially in individuals with chronic pain, where pharmacological treatment has achieved modest results, increasing the need to improve non-pharmacological approaches [22-24] and comprehensive management [24,25].

Here, we endeavor to determine the effect of SQ on pain in Chilean individuals affected by MSD, accounting for the effect of sex and pain duration. We approached the measurement of pain as multifactorial, considering intensity, distress and interference in daily activities [26]. We expected to find poor SQ to be associated with higher levels of pain and being female, and pain of longer duration to be associated with poor SQ and higher levels of pain.

\section{Materials and Methods}

\subsection{Participants}

A cross-sectional and analytical design was used. Individuals with either acute or chronic MSD were recruited by non-probabilistic consecutive sampling. Namely, each consecutive eligible patient who presented for MSD care during a defined period of time (from July 2019 to April 2020) was eligible to take part in this study [27,28]. They underwent physical therapy in two university rehabilitation centers specialized in MSD in southern Chile. The major MSD (i.e., low back pain, neck pain, osteoarthritis) and other MSD (e.g., disorders of synovium and tendon and other soft tissue disorders) are most frequently addressed. Upon entering rehabilitation (i.e., physical therapy), individuals 
were invited to participate provided that they met the following inclusion criteria: aged 18 years or over, speak Spanish and present a medical diagnosis of an MSD. Individuals who presented a neurological and/or cognitive condition that did not allow an adequate evaluation to be carried out were excluded. Likewise, individuals with severe uncompensated visual or hearing impairment were excluded. A total of 272 admissions were recorded during that period (87 admissions were in the city of Valdivia and 195 in the city of Temuco), of which 228 agreed to participate (mean age $=49.02$ years old, $\mathrm{SD}=17.93$; mean education $=13.2$ years of education, $\mathrm{SD}=3.21 ; 72.8 \%$ were women) and made up the final sample of this study. The participants were asked to provide sociodemographic information concerning age, sex, years of education, work status, marital status, personal monthly income, and MSD type. The descriptive characteristics of the sample are presented according to sex in Table 1.

Table 1. Sociodemographic characteristics by sex.

\begin{tabular}{|c|c|c|c|}
\hline Variable & $\begin{array}{l}\text { Women } \\
n=166\end{array}$ & $\begin{array}{c}\text { Men } \\
n=62\end{array}$ & $\begin{array}{c}\text { Total } \\
n=228\end{array}$ \\
\hline Age, Md (IQR) & $53.5(40-66)$ & $42(25-58)$ & $51.5(30-64)$ \\
\hline Years of education, Md (IQR) & $12(12-15)$ & $12(12-16)$ & $12(12-15)$ \\
\hline \multicolumn{4}{|l|}{ Work Status, $n(\%)$} \\
\hline Student & $24(14.5)$ & $17(27.4)$ & $41(18.0)$ \\
\hline Housewife & $69(41.6)$ & $0(0.0)$ & $69(30.3)$ \\
\hline Retired & $9(5.4)$ & 7 (11.3) & $16(7.0)$ \\
\hline Healthcare Services & $9(5.4)$ & $2(3.2)$ & $11(4.8)$ \\
\hline Service Occupation & $22(13.3)$ & $9(14.5)$ & $31(13.6)$ \\
\hline Office and Administration & $17(10.2)$ & $15(24.2)$ & $32(14.0)$ \\
\hline Transport & $1(0.6)$ & $3(4.8)$ & $4(1.8)$ \\
\hline Education and Library & $11(6.6)$ & $3(4.8)$ & $14(6.1)$ \\
\hline Others & $4(2.4)$ & $6(9.7)$ & $10(4.4)$ \\
\hline \multicolumn{4}{|l|}{ Marital Status, $n(\%)$} \\
\hline Single & $65(39.2)$ & $32(51.6)$ & $97(42.5)$ \\
\hline Married & $52(31.3)$ & $22(35.5)$ & $74(32.5)$ \\
\hline Divorced & $19(11.4)$ & $3(4.8)$ & $22(9.7)$ \\
\hline Separated & $17(10.2)$ & $0(0.0)$ & $17(7.5)$ \\
\hline Widow/Widower & $8(4.8)$ & $0(0.0)$ & $8(3.5)$ \\
\hline Co-habitation & $5(3.0)$ & $5(8.1)$ & $10(4.4)$ \\
\hline \multicolumn{4}{|l|}{ Monthly Income in USD, $n(\%)$} \\
\hline Less than 250 & $30(18.1)$ & 7 (11.3) & $37(16.2)$ \\
\hline $251-500$ & $76(45.8)$ & $20(32.3)$ & $96(42.1)$ \\
\hline $501-1000$ & $34(20.5)$ & $14(22.6)$ & $48(21.1)$ \\
\hline $1001-1500$ & $12(7.2)$ & $10(16.1)$ & $22(9.7)$ \\
\hline More than 1500 & $14(8.4)$ & $11(17.7)$ & $25(11.0)$ \\
\hline \multicolumn{4}{|l|}{ Type of MSD, $n(\%)$} \\
\hline Cervical & $10(6.0)$ & $3(4.8)$ & $13(5.7)$ \\
\hline Dorsal-Lumbar & $28(16.9)$ & $8(12.9)$ & $36(15.8)$ \\
\hline UL No-Trauma & $49(29.5)$ & $15(24.2)$ & $64(28.1)$ \\
\hline UL Trauma & $6(3.6)$ & $3(4.8)$ & $9(3.9)$ \\
\hline LL No-Trauma & $66(39.8)$ & $25(40.3)$ & $91(39.9)$ \\
\hline LL Trauma & $7(4.2)$ & $8(12.9)$ & $15(6.6)$ \\
\hline
\end{tabular}

Note: Md, median; IQR, interquartile range (upper and lower limit); UL, upper limb; LL, lower limb.

\subsection{Instruments}

\subsubsection{Pain}

Pain was measured multidimensionally using a visual analog scale (VAS), since it is a highly reproducible instrument, quick and easy to apply [26]. The scale consisted of a horizontal $100 \mathrm{~mm}$ line, whose ends were labeled as the extremes of different expressions of pain.

Intensity of pain: The left end of the VAS indicated absence of pain (i.e., "no pain") and the right the greatest intensity (i.e., "worst pain imaginable"). The individual was 
asked to mark the point that best indicated perceived pain intensity to measure its distance with a ruler later. The intensity of the pain was measured at rest (i.e., without movement), movement (i.e., most painful movement), and the average pain of the last 7 days.

Interference related to pain: This describes how the pain interferes with the individual's daily activities [26]. The left end of the VAS indicated the absence of interference (i.e., "without interference"), and the right indicated the greatest interference (i.e., "unable to carry out their activities").

Distress relative to pain: This is described as a multifactorial unpleasant emotional experience of a psychological nature (cognitive, behavioral, and emotional), social or even spiritual, due to persistent or recurrent pain [26]. Participants were asked to rate pain-related distress experienced in the past week on the VAS. The left end indicated the absence of distress (i.e., "without distress relative to pain"), and the right indicated the most significant distress (i.e., "maximum distress relative to pain").

Duration of pain: This was evaluated by asking, "How many months have you suffered the current pain?"

\subsubsection{Sleep Quality}

SQ was measured using the Spanish version of the Pittsburgh Sleep Quality Index (PSQI) [29], a commonly used tool, practical and brief, which measures SQ in the last month. The PSQI consists of 24 self-rated questions, of which 19 are included to obtain the overall SQ score, which is expressed on a scale of 0-21 points; a higher score indicates a worse SQ. From the global score, the evaluated individuals can be classified as having "Good SQ" ( $\leq 5$ PSQI) or "Poor SQ" (>5 PSQI), with a sensitivity of $89.6 \%$ and a specificity of $86.5 \%$, according to Buysse et al. [30]. The Spanish version has demonstrated good internal consistency $(\alpha=0.78)$ [29].

\subsection{Procedure}

During admission to rehabilitation (i.e., physical therapy), the participants were informed about the purpose of this study and their participation. All participants endorsed their decision to participate in the study by signing the informed consent. The professional in charge of applying the instruments was specially instructed before starting the investigation (i.e., using clear and understandable language) and to reduce the possible biases associated with self-report instruments, adequate time and space were set aside in the interviews. The participants were asked to complete the self-reported questionnaires on a tablet. The data provided were collected and managed using the REDcap ${ }^{\circledR}$ electronic recording tool hosted by the Universidad de La Frontera. In some instances, the participant did not feel comfortable handling the tablet; in such cases, the interviewer used it. All tests concerning the present study were carried out during the first physical therapy session, namely, before the patients started any treatment. The patients then followed the treatments that the physical therapist at the centers deemed appropriate regardless of the study.

The anonymity of the participant was protected. Each has a secret ID known only by the researchers, which was used throughout the process, including the possible publications that could derive from this investigation. This study followed the Guidelines of the Declaration of Helsinki [31] and was approved by the Ethics Committee of the Universidad Autónoma de Chile (No. 62-18).

\subsection{Data Analysis}

Descriptive statistics were used. The Shapiro-Wilk test showed that the quantitative variables did not comply with the assumption of normality. Thus, medians and interquartile range (IQR) were estimated. Quantitative and qualitative variables were compared according to sex by means of Mann-Whitney $U$ test and chi-squared test $\left(\chi^{2}\right)$, respectively.

Structural equation modeling (SEM) was performed to analyze the SQ effect on pain, controlling for sex and duration of pain. SEM comprises a set of robust multivariate analysis techniques-with greater statistical power as compared to other statistical techniques-that 
allow to test causal relationships among variables while also correcting for measurement error [32]. In brief, SEM allowed us to model simultaneously the relationships between the variables of interest and their directionality based on the proposed hypothesis. Accordingly, the latent variable pain was created. In line with Treede et al. [26], the variable Pain included the following factors: pain intensity (static, at movement and average of the last 7 days), interference of pain in daily activities and distress relative to pain. A model was analyzed in which the $S Q$ variable predicts the pain variable based on the current evidence describing that SQ predicts pain more strongly than pain predicts SQ [4-6]. Additionally, the variables sex and duration of pain were included in the model to control SQ and pain. The hypothesized SEM is described graphically in Figure 1. For the sample size calculation, 10 participants were estimated for every free parameter; thus, a minimum of 180 individuals were considered for the present study [33].

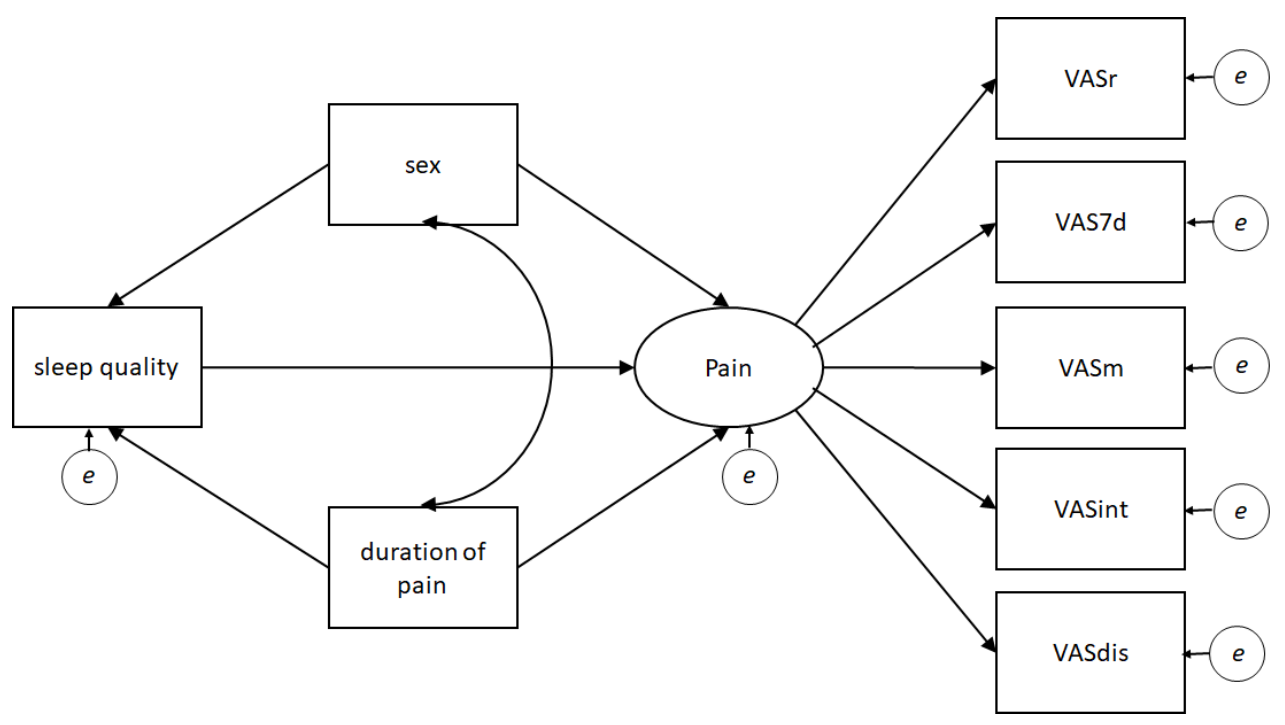

Figure 1. Hypothesized structural equation model. Note: The oval represents the latent variable (i.e., pain), the rectangles the indicators (i.e., measured variables), and the small circles the errors. VAS, visual analog scale; VASr, VAS at rest; VAS7d, average VAS 7 days; VASm, VAS at movement; VASint, VAS pain interference; VASdis, VAS distress relative to pain.

Correlational analyses were used to evaluate the association between SQ (i.e., PSQI score) and pain (each variable included in the SEM model) among individuals with MSD by means of Spearman's Rho.

Mardia's test was performed to analyze multivariate normality. As the assumption of normality was not fulfilled $(p<0.001)$, a maximum likelihood estimation with Santorra-Bentler correction was performed. The goodness-of-fit index was determined considering $\chi^{2}$, and as limit values the comparative fit index (CFI $\left.\geq 0.95\right)$, Tucker-Lewis index (TLI $\geq 0.90$ ), the root mean square error of approximation (RMSEA $\leq 0.06$ ), and the standardized root mean square residual (SRMR $\leq 0.08$ ), according to the cut-off scores established by $\mathrm{Hu}$ and Bentler [34]. There were no missing data in the study.

The statistical analysis was performed with the Stata 14 software.

\section{Results}

Descriptive results by sex are presented in Table 2. Older age and more significant pain (all variables/measures) were observed in women, except pain duration, which showed no differences between men and women. In addition, women showed higher PSQI scores (i.e., poor SQ) and higher frequencies of poor SQ. Table 3 presents Spearman's Rho correlation coefficient. 
Table 2. Clinical characteristics by sex.

\begin{tabular}{lcccc}
\hline \multicolumn{1}{c}{ Variable } & $\begin{array}{c}\text { Women } \\
\mathbf{n = 1 6 6}\end{array}$ & $\begin{array}{c}\text { Men } \\
\mathbf{n = 6 2}\end{array}$ & $\boldsymbol{p}$-Value & $\begin{array}{c}\text { Total } \\
\boldsymbol{n} \mathbf{2 2 8}\end{array}$ \\
\hline Pain intensity at rest, Md (IQR) & $29.5(5-54)$ & $15.5(0-32)$ & $0.003^{* *}$ & $25(3-49)$ \\
Pain intensity at movement, Md (IQR) & $73(53-86)$ & $64.5(33-84)$ & $0.048^{*}$ & $71(50-85)$ \\
Pain intensity 7 days, Md (IQR) & $62.5(41-76)$ & $46.5(19-70)$ & $0.001^{* *}$ & $58(32.5-75)$ \\
Interference of daily activities, Md (IQR) & $65(49-84)$ & $50(18-72)$ & $<0.001^{* * *}$ & $61(42-80)$ \\
Distress relative to pain, Md (IQR) & $74(52-88)$ & $45(20-81)$ & $<0.001^{* * *}$ & $71.5(41-86.5)$ \\
Duration of pain (months), Md (IQR) & $6(2-24)$ & $6(3-12)$ & 0.377 & $6(2-13.5)$ \\
Total score PSQI, Md (IQR) & $10(7-12)$ & $7(5-9)$ & $<0.001^{* * *}$ & $9(6-11)$ \\
PSQI categories, $n$ (\%) & & & & \\
$\quad$ Good sleep quality & $22(13.25)$ & $17(27.42)$ & $0.011^{*}$ & $39(17.11)$ \\
$\quad$ Poor sleep quality & $144(86.75)$ & $45(72.58)$ & & $189(82.89)$ \\
\hline
\end{tabular}

Note: Md, median; IQR, interquartile range (upper and lower limit); PSQI, Pittsburgh Sleep Quality Index; Mann-Whitney $\mathrm{U}$ test for continuous variables and $\chi 2$ for categorical variables. ${ }^{*} p<0.05,{ }^{* *} p<0.01,{ }^{* * *} p<0.001$.

Table 3. Bivariate correlations among the variables included in the structural equation modeling.

\begin{tabular}{lcccccccc}
\hline \multicolumn{1}{c}{ Variable } & $\mathbf{1}$ & $\mathbf{2}$ & $\mathbf{3}$ & $\mathbf{4}$ & $\mathbf{5}$ & $\mathbf{6}$ & $\mathbf{7}$ & $\mathbf{8}$ \\
\hline 1. PSQI & & & & & & & & \\
2. Sex & $0.27^{* * *}$ & & & & & & & \\
3. Duration & 0.002 & -0.06 & & & & & & \\
4. VASe & $0.22^{* * *}$ & $-0.20^{* *}$ & -0.004 & & & & & \\
5. VAS7d & $0.26^{* * *}$ & $-0.22^{* *}$ & 0.01 & $0.54^{* * *}$ & & & & \\
6. VASdyn & $0.25^{* * *}$ & $-0.13^{*}$ & 0.02 & $0.42^{* * *}$ & $0.66^{* * *}$ & & \\
7. VASint & $0.31^{* * *}$ & $-0.23^{* * *}$ & 0.04 & $0.39^{* * *}$ & $0.61^{* * *}$ & $0.63^{* * *}$ & & \\
8. VASdis & $0.23^{* * *}$ & $-0.22^{* * *}$ & 0.01 & $0.33^{* * *}$ & $0.53^{* * *}$ & $0.57^{* * *}$ & $0.65^{* * *}$ &
\end{tabular}

Note: PSQI, Pittsburgh Sleep Quality Index; Duration, pain durations; VASe, VAS at rest; VAS7d, average VAS 7 days; VASdyn, VAS at movement; VASint, VAS pain interference; VASdis, VAS distress relative to pain. Code for women $=0$ and men $=1 .{ }^{*} p<0.05,{ }^{* *} p<0.01,{ }^{* * *} p<0.001$.

As a first step, the latent variable pain was evaluated according to its goodnessof-fit indicators. A covariance between static pain intensity and mean pain intensity of the last 7 days was modeled. The model provided a good fit for the data $\chi^{2}(4)=3.88$, $p=0.423$; CFI $=1.0$; TLI $=1.0$; RMSEA $<0.001,90 \%$ CI $(0.00,0.10)$; SRMR $=0.01$. Next, the entire model was evaluated, showing its results with standardized coefficients in Figure 2, indicating that poor SQ predicts greater pain $(\beta=0.29,95 \%$ CI $(0.16,0.42)$, $p<0.001)$. Sex had a direct effect on SQ and pain. Given that the variable sex was coded as 0 for women and 1 for men, it is evidenced that women have worse SQ than men $(\beta=-0.27,95 \% \mathrm{CI}(-0.39,-0.15), p<0.001)$ and greater pain $(\beta=-0.20,95 \% \mathrm{CI}(-0.34$, $-0.05), p<0.001)$. Pain duration has no effect on SQ $(\beta=-0.05,95 \%$ CI $(-0.19,0.08)$, $p=0.44)$ nor on pain $(\beta=0.05,95 \% \mathrm{CI}(-0.05,0.16), p=0.33)$. Even so, pain duration covaried with sex $(\beta=-0.12,95 \% \mathrm{CI}(-0.20,0.04), p=0.005)$. The fit of this model was excellent $\left(\chi^{2}(16)=17.68, p=0.34 ; \mathrm{CFI}=0.99 ; \mathrm{TLI}=0.99 ; \mathrm{RMSEA}=0.02,90 \%\right.$ IC $(0.00,0.07)$; $\mathrm{SRMR}=0.02)$. Hence, it may be suggested that $S Q$ has an effect on pain, that women show poor SQ and greater pain than men, and lastly, that pain duration has no effect on SQ or pain in these Chilean adults with MSD. 


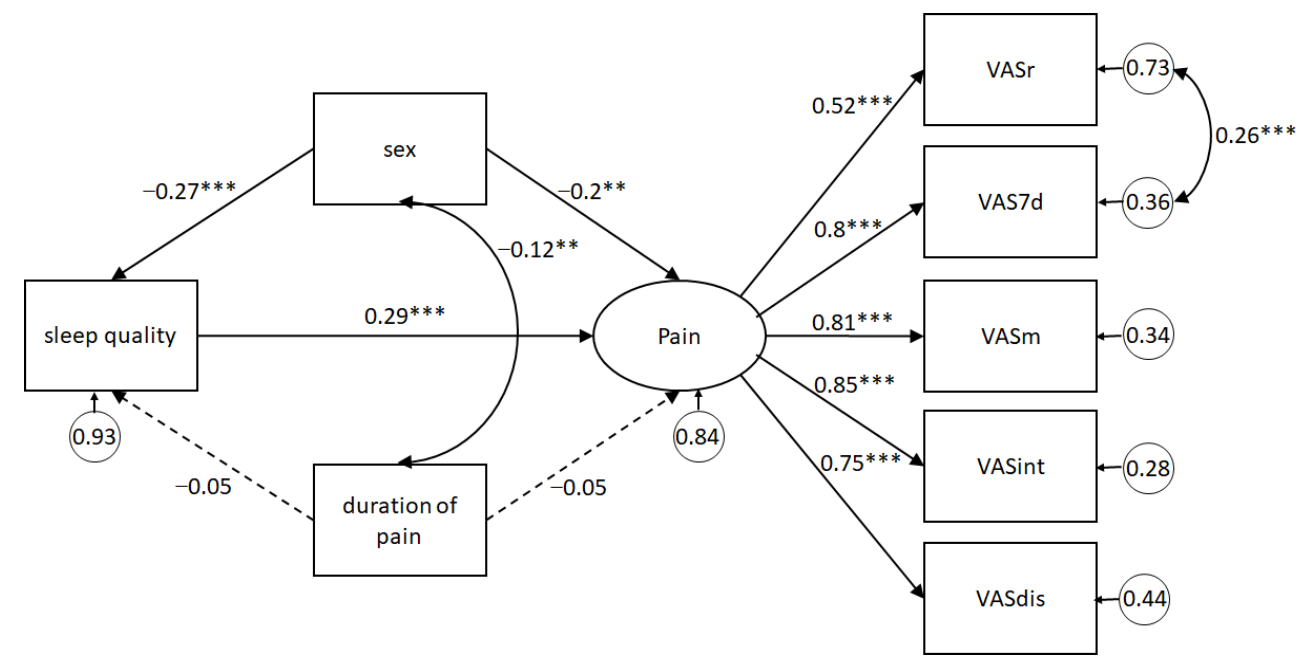

Figure 2. Structural equation model predicting pain from sleep quality, controlling for sex and pain duration. Note: Statistics are standardized regression coefficients. Dotted lines represent nonsignificant relations; bold lines represent significant paths. The curve lines correspond to covariation between variables or their errors. VASr, VAS at rest; VAS7d, average VAS 7 days; VASm, VAS at movement; VASint, VAS pain interference; VASdis, VAS distress relative to pain. ${ }^{*} p<0.05,{ }^{* *} p<0.01$, *** $p<0.001$.

\section{Discussion}

The present study aimed to determine the SQ effect on pain in Chilean individuals with MSD, controlling for sex and pain duration. Our findings support the hypothesis that SQ predicts greater pain in individuals with MSD, which are in line with previous studies [12,35]. The Hispanic-American studies, conducted in Mexico [17,19] and Peru [18], specifically, provide descriptive information about the prevalence of SQ and pain in the studied population. Furthermore, they present poor methodological and results reporting in terms of writing and incomplete information $[17,18]$, and one of them had a small sample size, which could lead to not finding a relation between SQ and pain [19]. Furthermore, Mariños et al. [18] measured specific sleep impairments (apnea, insomnia, and somnolence) without accurate instruments. Thus, our investigation contributes to the corpus of knowledge on this relation, specifically to understanding of the link between SQ and pain in individuals with MSD in a developing country like Chile, expanding the radius of evidence beyond developed and English-speaking countries as proposed by Stubbs et al. [20] and Afolalu et al. [4]. This is relevant given that, unlike developed countries, in Chile there is marked inequity in access to health, especially mental health (where sleep impairments are framed) [36] as well as in the access and quality of treatment for MSD, which the latter are perceived by our population as deficient or modest [36,37].

A high frequency of poor SQ has been described in the population with MSD, reporting up to $86 \%$ [38], comparable with the frequency found in our sample $(82.89 \%)$. Such data support the idea that SQ should be considered in the clinical management of individuals with MSD.

The variable sex had a direct effect on SQ and pain. Thus, women presented a higher percentage of poor SQ than men $(86.75 \%$ vs. $72.58 \%$, respectively). This is in line with the results of various previous studies that describe women as having higher levels of poor SQ in objective and subjective measurements $[5,10]$. This can be explained by the alteration of sleep architecture caused by menstrual cycles, pregnancy and menopause, in addition to higher risk factors for poor SQ such as depression and anxiety [39]. Regarding the effect of sex on pain, our results show a higher level of pain in women in agreement with previous studies $[10,40,41]$. This difference could be due to multiple mechanisms that include differences in endogenous opioid function, sexual hormone effects, affective/cognitive influences [42], as well as the contribution of social factors such as gender 
role stereotypes [43,44] and other responsibilities related to particular stages of life, such as those related to childcare or work-life balance [45].

Pain duration had no effect on SQ or on pain. It should be noted that the evidence of the effect of pain duration on SQ is still controversial. On the one hand, studies by Nicassio et al. [14] and Luyster et al. [13] in individuals with rheumatoid arthritis (RA), a disease characterized by the presence of pain, found no relation between the disease duration and PSQI score (i.e., SQ). On the other hand, Sezgin et al. [10] showed that pain duration had adverse effects on SQ for individuals with chronic low back pain (CLBP). Similarly, evidence on the effect of pain duration on pain intensity is contradictory. The data from Nicassio et al. [14], Luyster et al. [13] and Van Looveren et al. [6] showed no effect, while $\mathrm{O}^{\prime}$ Brien et al. [12] described that duration of pain predicts a more significant pain in CLBP individuals. The difference between our results and those of Sezgin et al. [10] and $\mathrm{O}^{\prime}$ Brien et al. [12] regarding the effect of pain duration on SQ and pain could be down to the heterogeneity of diagnoses and pain durations of the individuals included in our study ( $35.96 \%$ acute vs. $64.04 \%$ chronic). In addition, it should be considered that individuals with CLBP and RA are classified differently according to the mechanism underlying the pain. CLBP is classified as primary chronic pain, which is not associated with tissue damage but with complex multidimensional pain characteristics [26,46]. Pain due to RA is classified as secondary chronic pain and exhibits characteristics of inflammatory pain, relating to a basal pathology. This difference in underlying mechanisms of pain could modify the SQ-pain association. Likewise, it should be noted that Nicassio et al. [14] and Luyster et al. [13] considered the disease duration and not precisely the duration of pain. However, more research is needed to clarify this aspect.

Further, our results revealed a direct and moderate relationship between SQ and both pain intensity and pain interference, although lower than those reported in previous studies (i.e., between 0.37 and 0.55 ) $[13,14,23,38]$. This could be due to the studies mentioned above focusing particularly on the association between SQ and chronic pain. It is possible that the inclusion of individuals with acute pain in this study (35.96\%) might have decreased the magnitude of association between SQ and pain, suggesting that the relationship is stronger between SQ and chronic pain.

One aspect to highlight in the present study is the SEM analysis used. This robust statistic technique allows for model latent variables, reporting the common variation of several indicators contingent on a larger construct. In this vein, following Treede et al. [26], this study addressed the measurement of pain from a multidimensional perspective and considered intensity, distress and interference in daily activities to focus on characteristics of severity, temporality and psychosocial factors. This difference with other studies that use only one dimension of pain (often intensity) is fundamental. This is related to the International Association of the Study of Pain (IASP) proposal, which calls on healthcare professionals to approach pain from a more complex perspective [26,47].

Our study is not free of limitations. First, we used non-probability sampling, which might affect the generalizability of our findings. Indeed, the relationship between SQ and pain may vary in other populations affected by acute or chronic pain (i.e., fibromyalgia, headache/migraine, idiopathic pain disorders, and cancer-related pain). In addition, it should be considered that sleep habits of specific populations (i.e., people who work night shifts, such as healthcare professionals) could modulate the effect of poor SQ on pain. This aspect should be clarified in future studies. Second, our sample was composed mostly of women, although a resent systematic review revealed that a significant number of studies include mainly women in their samples [16]. Like many other studies, our sample includes a relatively large number of students. Thus, the generalization of the present results must be contrasted against more heterogeneous samples. However, it should be noted that the current findings might be particularly relevant for the vast corpus of studies that include a large number of students in their samples [48]. Furthermore, the fact that a large number of students were recruited was not determined by the consecutive sampling used in the present study but by the nature of the rehabilitation centers (i.e., university rehabilitation 
centers specialized in MSD), whose regular patients include a significant proportion of students with distinctive characteristics such as insufficient sleep [49] and high degree of stress. Finally, we only included subjective, self-reported sleep measures. Although this might be considered a limitation, some authors indicate that self-reported measures of SQ should be considered the gold standard over polysomnography (PSG) based on the idea that PSG can present some variability and imprecisions. It only has the capacity to capture a particular moment of a condition that often spans a lifetime [12,50]. Finally, it should be emphasized that pain is a complex experience that includes sensory, emotional, cognitive, and social factors [51-53] that should be addressed in future research on the association of sleep and pain for a richer and more holistic interpretation.

\section{Conclusions}

All in all, our findings suggest that poor SQ predicts higher pain levels, highlighting an important factor to be considered in the approach of pain in individuals with MSD and, possibly, chronic pain prevention. These findings are relevant for those who suffer from MSD and for the healthcare professionals who treat them. We consider these results a starting point in understanding the association between SQ and pain in developing countries. Future research could address this relationship in clinical populations (e.g., shoulder pain, osteoarthritis, tendinopathy), implement greater control of confounding factors, and determine whether the improvement of poor SQ has a positive impact on pain in individuals with MSD.

Author Contributions: Conceptualization, C.B.-S., H.B.-A., J.A., C.L.-A., D.B.-A., R.G.-B., M.V.-T. and G.G.-G.; methodology, C.B.-S., J.A. and R.G.-B.; formal analysis, C.B.-S. and J.A.; investigation, C.B.-S., C.L.-A., D.B.-A. and M.V.-T.; resources, C.B.-S. and G.G.-G.; data curation, C.B.-S.; writing-original draft preparation, C.B.-S., H.B.-A., J.A., R.G.-B., M.V.-T. and G.G.-G.; writing-review and editing, C.B.-S., H.B.-A., J.A., C.L.-A., D.B.-A., R.G.-B., M.V.-T. and G.G.-G.; project administration, C.B.-S. and G.G.-G.; funding acquisition, C.B.-S. and G.G.-G. All authors have read and agreed to the published version of the manuscript.

Funding: This research was funded by DIUFRO (project code DI20-0046) and by ANID-Chile, FONDECYT (project code 1200368) and FONIS (project code SA19I0003).

Institutional Review Board Statement: The study was conducted according to the guidelines of the Declaration of Helsinki, and approved by the Ethics Committee of Universidad Autónoma de Chile (No. 62-18).

Informed Consent Statement: Informed consent was obtained from all subjects involved in the study.

Data Availability Statement: The data that support the findings of this study are available from the corresponding author, upon reasonable request.

Acknowledgments: Thanks to Patricia Obreque Cardenas and Helen M. Lowry for proofreading the article.

Conflicts of Interest: The authors declare no conflict of interest. The funders had no role in the design of the study; in the collection, analyses, or interpretation of data; in the writing of the manuscript, or in the decision to publish the results.

\section{References}

1. Cieza, A.; Causey, K.; Kamenov, K.; Hanson, S.W.; Chatterji, S.; Vos, T. Global estimates of the need for rehabilitation based on the Global Burden of Disease study 2019: A systematic analysis for the Global Burden of Disease Study 2019. Lancet 2020, 396, 2006-2017. [CrossRef]

2. Koffel, E.; Kroenke, K.; Bair, M.J.; Leverty, D.; Polusny, M.; Krebs, E. The bidirectional relationship between sleep complaints and pain: Analysis of data from a randomized trial. Health Psychol. 2016, 35, 41-49. [CrossRef] [PubMed]

3. Smith, M.T.; Haythornthwaite, J.A. How do sleep disturbance and chronic pain inter-relate? Insights from the longitudinal and cognitive-behavioral clinical trials literature. Sleep Med. Rev. 2004, 8, 119-132. [CrossRef]

4. Afolalu, E.F.; Ramlee, F.; Tang, N.K. Effects of sleep changes on pain-related health outcomes in the general population: A systematic review of longitudinal studies with exploratory meta-analysis. Sleep Med. Rev. 2017, 39, 82-97. [CrossRef] [PubMed] 
5. Finan, P.H.; Goodin, B.R.; Smith, M.T. The Association of Sleep and Pain: An Update and a Path Forward. J. Pain 2013, 14, 1539-1552. [CrossRef]

6. Van Looveren, E.; Bilterys, T.; Munneke, W.; Cagnie, B.; Ickmans, K.; Mairesse, O.; Malfliet, A.; De Baets, L.; Nijs, J.; Goubert, D.; et al. The Association between Sleep and Chronic Spinal Pain: A Systematic Review from the Last Decade. J. Clin. Med. 2021, 10, 3836. [CrossRef] [PubMed]

7. Lautenbacher, S.; Kundermann, B.; Krieg, J.-C.; Lautenbacher, S.; Kundermann, B.; Krieg, J.-C. Sleep deprivation and pain perception. Sleep Med. Rev. 2006, 10, 357-369. [CrossRef] [PubMed]

8. Miettinen, T.; Mäntyselkä, P.; Hagelberg, N.; Mustola, S.; Kalso, E.; Lötsch, J. Machine learning suggests sleep as a core factor in chronic pain. Pain 2020, 162, 109-123. [CrossRef]

9. Haack, M.; Simpson, N.; Sethna, N.; Kaur, S.; Mullington, J. Sleep deficiency and chronic pain: Potential underlying mechanisms and clinical implications. Neuropsychopharmacology 2019, 45, 205-216. [CrossRef]

10. Sezgin, M.; Hasanefendioğlu, E.Z.; Sungur, M.A.; Incel, N.A.; Çimen, B.; Kanık, A.; Şahin, G. Sleep quality in patients with chronic low back pain: A cross-sectional study assesing its relations with pain, functional status and quality of life. J. Back Musculoskelet. Rehabil. 2015, 28, 433-441. [CrossRef] [PubMed]

11. Bascour-Sandoval, C.; Norambuena-Noches, Y.; Monrroy-Uarac, M.; Flández-Valderrama, J.; Gálvez-García, G.; Gajardo-Burgos, R. Association between Sleep Quality and Pain in Young Amateur Athletes. Rev. Bras. Med. Esporte 2021, 27, 165-169. [CrossRef]

12. O'Brien, E.M.; Waxenberg, L.B.; Atchison, J.W.; Gremillion, H.A.; Staud, R.M.; McCrae, C.; Robinson, M.E. Negative Mood Mediates the Effect of Poor Sleep on Pain Among Chronic Pain Patients. Clin. J. Pain 2010, 26, 310-319. [CrossRef] [PubMed]

13. Luyster, F.S.; Chasens, E.R.; Wasko, M.C.M.; Dunbar-Jacob, J. Sleep Quality and Functional Disability in Patients with Rheumatoid Arthritis. J. Clin. Sleep Med. 2011, 7, 49-55. [CrossRef] [PubMed]

14. Nicassio, P.M.; Ormseth, S.R.; Kay, M.; Custodio, M.; Irwin, M.R.; Olmstead, R.; Weisman, M.H. The contribution of pain and depression to self-reported sleep disturbance in patients with rheumatoid arthritis. Pain 2012, 153, 107-112. [CrossRef]

15. Kelly, G.A.; Blake, C.; Power, C.; O’Keeffe, D.; Fullen, B.M. The Association between Chronic Low Back Pain and Sleep. Clin. J. Pain 2011, 27, 169-181. [CrossRef]

16. Mathias, J.; Cant, M.; Burke, A. Sleep disturbances and sleep disorders in adults living with chronic pain: A meta-analysis. Sleep Med. 2018, 52, 198-210. [CrossRef]

17. Covarrubias-Gómez, A.; Villegas-Sotelo, E.; Mendoza-Reyes, J.J. Con Dolor Crónico De Origen No-Oncológico. Rev. Mex. Anestesiol. 2014, 37, 253-259.

18. Marinos, A.; Kawano, J.; Juárez, A.; Ruiz, P.; Vizcarra, D. Trastornos del sueño y dolor: Estudio transversal descriptivo en un instituto de medicina de sueño de Lima. Rev. Neuro-Psiquiatr. 2012, 74, 264-269. [CrossRef]

19. Navarro-Aquino, N.; Guevara-López, U.; Serratos-Vázquez, M.C.; Pérez-Atanasio, J.M. Prevalencia de alteraciones en la calidad del sueño en adultos mayores con dolor crónico musculoesquelético. Rev. Mex. Anestesiol. 2015, 38, 79-84.

20. Stubbs, B.; Vancampfort, D.; Thompson, T.; Veronese, N.; Carvalho, A.F.; Solmi, M.; Mugisha, J.; Schofield, P.; Prina, M.; Smith, L.; et al. Pain and severe sleep disturbance in the general population: Primary data and meta-analysis from 240,820 people across 45 low- and middle-income countries. Gen. Hosp. Psychiatry 2018, 53, 52-58. [CrossRef]

21. Chun, M.Y.; Cho, B.-J.; Yoo, S.H.; Oh, B.; Kang, J.-S.; Yeon, C. Association between sleep duration and musculoskeletal pain. Medicine 2018, 97, e13656. [CrossRef]

22. Nijs, J.; Mairesse, O.; Neu, D.; Leysen, L.; Danneels, L.; Cagnie, B.; Meeus, M.; Moens, M.; Ickmans, K.; Goubert, D. Sleep disturbances in chronic pain: Neurobiology, assessment, and treatment in physical therapist practice. Phys. Ther. 2018, 98, 325-335. [CrossRef]

23. van de Water, A.T.; Eadie, J.; Hurley, D.A. Investigation of sleep disturbance in chronic low back pain: An age- and gender-matched case-control study over a 7-night period. Man. Ther. 2011, 16, 550-556. [CrossRef] [PubMed]

24. Andersen, M.L.; Araujo, P.; Frange, C.; Tufik, S. Sleep Disturbance and Pain. Chest 2018, 154, 1249-1259. [CrossRef]

25. Marin, R.; Cyhan, T.; Miklos, W. Sleep Disturbance in Patients with Chronic Low Back Pain. Am. J. Phys. Med. Rehabil. 2006, 85, 430-435. [CrossRef]

26. Treede, R.-D.; Rief, W.; Barke, A.; Aziz, Q.; Bennett, M.I.; Benoliel, R.; Cohen, M.; Evers, S.; Finnerup, N.B.; First, M.B.; et al. Chronic pain as a symptom or a disease: The IASP Classification of Chronic Pain for the International Classification of Diseases (ICD-11). Pain 2019, 160, 19-27. [CrossRef]

27. Leopold, S.S. Editorial: Words and Meaning in Scientific Reporting: Consecutive, Prospective, and Significant. Clin. Orthop. Relat. Res. 2013, 471, 2731-2732. [CrossRef]

28. Setia, M.S. Methodology series module 5: Sampling strategies. Indian J. Dermatol. 2016, 61, 505-509. [CrossRef] [PubMed]

29. Escobar-Córdoba, F.; Eslava-Schmalbach, J. Colombian validation of the Pittsburgh Sleep Quality Index. Rev. Neurol. 2005, 40, 150-155. [CrossRef] [PubMed]

30. Buysse, D.J.; Reynolds, C.F.; Monk, T.H.; Berman, S.R.; Kupfer, D.J. The Pittsburgh sleep quality index: A new instrument for psychiatric practice and research. Psychiatry Res. 1989, 28, 193-213. [CrossRef]

31. World Medical Association World Medical Association Declaration of Helsinki. JAMA 2013, 310, 2191-2194. [CrossRef]

32. Beran, T.N.; Violato, C. Structural equation modeling in medical research: A primer. BMC Res. Notes 2010, 3, 267. [CrossRef]

33. Schreiber, J.; Nora, A.; Stage, F.K.; Barlow, E.A.; King, J. Reporting Structural Equation Modeling and Confirmatory Factor Analysis Results: A Review. J. Educ. Res. 2006, 99, 323-338. [CrossRef] 
34. Hu, L.; Bentler, P.M. Cutoff criteria for fit indexes in covariance structure analysis: Conventional criteria versus new alternatives. Struct. Equ. Model. A Multidiscip. J. 1999, 6, 1-55. [CrossRef]

35. Tang, N.K.Y.; Wright, K.J.; Salkovskis, P.M. Prevalence and correlates of clinical insomnia co-occurring with chronic back pain. J. Sleep Res. 2007, 16, 85-95. [CrossRef]

36. Ministerio de Salud de Chile [MINSAL]. Salud Mental en la Atención Primaria de Salud: Orientaciones; Ministerio de Salud: Santiago, Chile, 2018; Available online: http:/ /www.bibliotecaminsal.cl/wp/wp-content/uploads/2018/01/016.Salud-Mental. pdf (accessed on 4 September 2021).

37. Bilbeny, N. Dolor Crónico en Chile. Rev. Médica Clínica Las Condes 2019, 30, 397-406. [CrossRef]

38. Harrison, L.; Wilson, S.; Heron, J.; Stannard, C.; Munafò, M.R. Exploring the associations shared by mood, pain-related attention and pain outcomes related to sleep disturbance in a chronic pain sample. Psychol. Health 2016, 31, 565-577. [CrossRef] [PubMed]

39. Krishnan, V.; Collop, N.A. Gender differences in sleep disorders. Curr. Opin. Pulm. Med. 2006, 12, 383-389. [CrossRef]

40. Rodrigues-De-Souza, D.P.; Fernández-De-Las-Peñas, C.; Vallejo, F.J.M.; Blanco-Blanco, J.F.; Moro-Gutiérrez, L.; AlburquerqueSendín, F. Differences in pain perception, health-related quality of life, disability, mood, and sleep between Brazilian and Spanish people with chronic non-specific low back pain. Braz. J. Phys. Ther. 2016, 20, 412-421. [CrossRef]

41. Bonvanie, I.J.; Oldehinkel, A.J.; Rosmalen, J.G.; Janssens, K.A. Sleep problems and pain. Pain 2016, 157, 957-963. [CrossRef] [PubMed]

42. Fillingim, R.B.; King, C.D.; Ribeiro-Dasilva, M.C.; Rahim-Williams, B.; Riley, J.L. Sex, Gender, and Pain: A Review of Recent Clinical and Experimental Findings. J. Pain 2009, 10, 447-485. [CrossRef]

43. Schwarz, K.A.; Sprenger, C.; Hidalgo, P.; Pfister, R.; Diekhof, E.; Büchel, C. How Stereotypes Affect Pain. Sci. Rep. 2019, 9, 8626. [CrossRef] [PubMed]

44. Alabas, O.; Tashani, O.; Tabasam, G.; Johnson, M. Gender role affects experimental pain responses: A systematic review with meta-analysis. Eur. J. Pain 2012, 16, 1211-1223. [CrossRef]

45. Pengo, M.; Won, C.H.; Bourjeily, G. Sleep in Women Across the Life Span. Chest 2018, 154, 196-206. [CrossRef]

46. O'Sullivan, P.; Caneiro, J.; O'Keeffe, M.; Smith, A.; Dankaerts, W.; Fersum, K.; O'Sullivan, K. Cognitive Functional Therapy: An Integrated Behavioral Approach for the Targeted Management of Disabling Low Back Pain. Phys. Ther. 2018, 98, 408-423. [CrossRef]

47. International Pain Summit of the International Association of the Study of Pain, I. Declaration of Montréal: Declaration that access to pain management is a fundamental human right. J. Pain Palliat. Care Pharmacother. 2011, 25, 29-31. [CrossRef]

48. Hanel, P.H.P.; Vione, K.C. Do Student Samples Provide an Accurate Estimate of the General Public? PLoS ONE 2016, 11, e0168354. [CrossRef] [PubMed]

49. Owens, J.; Adolescent Sleep Working Group. Committee on Adolescence Insufficient Sleep in Adolescents and Young Adults: An Update on Causes and Consequences. Pediatrics 2014, 134, e921-e932. [CrossRef]

50. Finan, P.H. Sleep, pain, and the problem with treating sleep to relieve pain. Sleep Med. 2018, 52, 211-212. [CrossRef]

51. Bascour-Sandoval, C.; Salgado-Salgado, S.; Milan, E.G.; Fernández-Gómez, J.; Michael, G.A.; Gálvez-García, G. Pain and Distraction According to Sensory Modalities: Current Findings and Future Directions. Pain Pr. 2019, 19, 686-702. [CrossRef] [PubMed]

52. Fillingim, R. Individual differences in pain: Understanding the mosaic that makes pain personal. Pain 2016, 158, S11-S18. [CrossRef] [PubMed]

53. Sluka, K.A.; George, S.Z. A New Definition of Pain: Update and Implications for Physical Therapist Practice and Rehabilitation Science. Phys. Ther. 2021, 101. [CrossRef] [PubMed] 